\title{
Pleural Malignant Mesothelioma by AJCC v7 Stage
}

National Cancer Institute

\section{Source}

National Cancer Institute. Pleural Malignant Mesothelioma by AJCC v7 Stage. NCI

Thesaurus. Code C136374.

A term that refers to the staging of pleural malignant mesothelioma, following the rules of the TNM AJCC V7 classification system. 